\title{
Dementia:Trauma and loss of personhood vs family as recuperative space
}

\author{
SARITA AGARWAL, SANGEETA JHAJHARIA
}

\begin{abstract}
The paper looks at the exploration in three Indian novels in English, of the hitherto glorified Indian family through the paradigm of dementia, examines the strained space called "home" in the shadow of dementia, and its transformation into a recuperative space with the help of support systems other than immediate family members.
\end{abstract}

These three recent texts have discussed this crippling condition; which earlier authors shied away from. Anuradha Roy's The Folded Earth (2012), Ranjit Lal's Our Nana was a Nutcase (2015), and Pankaj Varma's Silver Haze (2014), focus on the lifechanging effects of the deadly disease dementia. These literary texts opt for a non-medical approach through which the person suffering dementia is depicted, rather than dementia itself. The family becomes a narrative prism through which to view the changing equations in relationships, the erosion of the family structure, instead of the specific medical condition. In conclusion, one could say that families become the recuperative space for patients rather than medical facilities for long term care.

These writers do not focus much on the medicalisation of dementia or geriatric health issues. They do mention medical treatments, but the spotlight is on the family, not on clinical viewpoints or medical approaches.

Key words: Dementia, disorientation, trauma, deterioration, family space, caregivers.

Dementia is an umbrella term that refers to a number of symptoms caused by degenerative conditions affecting the brain. These conditions include: Alzheimer's (the most

Author: Sarita Agarwal (saritaagarwal18slas@modyuniversity.ac.in),PhD Scholar, School of Liberal Arts \& Sciences, Mody University, Lakshmangarh, Sikar. Rajasthan, INDIA; Sangeeta Jhajharia (corresponding author sangeetajhajharia.slas@modyuniversity.ac.in), Assistant Professor, School of Liberal Arts and S ciences, Mody University, Lakshmangarh, Sikar. Rajasthan, 332311 INDIA.

To cite: Agarwal S, Jhajharia S. Dementia: Trauma and loss of personhood vs. Family as recuperative space. Indian J Med Ethics. Published online on August 5, 2021.DOI: 10.20529/IJME.2021.059

Manuscript Editor: Rakhi Ghoshal

Peer Reviewer: Alok Sarin

C Indian Journal of Medical Ethics 2021 common form of dementia), vascular dementia (caused by a stroke), and Korsakoff's syndrome (associated with heavy alcohol use over a long period of time) (1). Dementia affects each person differently but the general symptoms include loss of memory, disorientation, confusion, communication difficulties, and changes in temperament. A person with dementia may be able to maintain a good quality of life for a number of years after it has been diagnosed but the symptoms become more severe over time. At an intermediate stage, these symptoms increase in severity and a person may also develop difficulties in recognising people and objects; lose track of time, and experience changes in behaviour. Finally, a person finds it hard to follow a conversation and recognise family members. Through this paper, the researcher analyses the layered issues of mental health in the three Indian novels in English.

\section{Dementia as family trauma}

For Diwan Sahib in The Folded Earth (2), Nana in Our Nana was a Nutcase (3) and Kamala in Silver Haze (4); the family setting is the space where the symptoms of dementia and related conditions are manifested. These novels document the instances wherein family members are the first to observe the individual's mental deterioration.

Nana's progressive dementia is revealed in his confusion, disorientation and forgetfulness in Lal's Our Nana was a Nutcase, "Often he would lose his way and take the car down bumpy narrow dead end tracks, insisting it was a short cut and then try reversing all the way back" (3:p 24). Nana who had never been late in dropping the grandchildren at school, forgets the road and asks the younger children to navigate. This is the first sign of dementia in him. He pays the "Neerameerabais" their salaries twice and buys sweets four times for the twins Dingaling and Dumpling. This is when the older children, Avantika and Harshita, first begin to wonder about Nana's mental condition.

In Silver Haze, there is a slow and steady decline in the mental abilities of Kamala. Kamala accuses the servants of stealing sweets when in fact she had given them the sweets herself. "For a long time I had a feeling that our domestics were stealing things from our home" (4: $p$ 236). This behaviour of Kamala alerts the family. Her fears about her husband and her son have increased - She is scared that her son Kamal has an office in an area where terror attacks were frequent, or that a 
hit and run accident had been "engineered" for the sake of property. She believes that her niece Meghna's husband "had engineered both the deaths so that he could inherit the property. I was sure that we were next in his hit list" (4: p. 226). These suspicions which were quite baseless were a product of her fragility brought on by dementia.

It is interesting to note that in both Silver Haze (4) and The Folded Earth (2); the protagonists have an uncanny sense of being exploited and manipulated. If Kamala is suspicious about a family member's eye on her property, then Diwan Sahib is secretive about his biggest treasure - the Edwina Mountbatten-Jawaharlal Nehru correspondence - he understands what lures his nephew to his home is those letters. Consequently, Diwan Sahib hides them before his health deteriorates further. Thus, dementia is not represented as the complete erosion of mental faculties - there are sharp moments of recognition of the realities in their relationships.

While dementia may totally erase the personhood of an individual (even making them forget who they are); the authors have chosen to protect the basic attribute of selfpreservation from this assault. Perhaps this could be attributed to the needs of a good "story".

In each of the three novels, the family experiences the onset and progress of dementia differently. In Our Nana was a Nutcase, the two young children find their grandfather's forgetfulness amusing and exploit it to their own benefit, while the elder two are more concerned (3). "I hope I'm wrong, I said in a strange hollow voice, but, it looks like Nana's getting, or has got, dementia or something like that" (3: p 70). However, four of them redefine their network of relationships, transforming themselves from dependent children to care-givers, and even guardians of the old man. In Silver Haze, the web of relationships, woven around the mother becomes strained. Kamala's paranoia becomes the source of annoyance and embarrassment to the younger members of the family, and the focus is on deteriorating familial relationships under the pressure of dementia (4). In The Folded Earth, Diwan Sahib's network of relationships is built not on blood relations but on his faithful servants, tenants and long-time friends who become his recuperative space till his last breath (2). The erosion of caring and worthy relationships because of loss of personhood is invariably linked in these texts.

A contrasting analysis of the three novels becomes interesting because it shows the different scenarios for care giving that can be imagined for a person suffering dementia. But a point to be noted here is that none of the scenarios are water tight and locked; different attributes of different types of caring driven by emotions can come to the fore in the care given to a patient. While a family member may be "annoyed or irritated" for a while and wouldn't provide as much emotional care as needed; the same person might feel nostalgia for her/his relationship with the affected person, and at a different time, might provide the best kind of emotional care.

Labelling behaviour towards the person with dementia as "wrong" or "right", or "good" or "evil" would be the wrong approach in understanding dementia, as the family too has to live with the effects of the condition on that person. They might feel frustrated, sad and helpless due to the fact that a person they knew as completely different has been reduced to a fraction of their own old self. They might even be overwhelmed by the lifestyle changes that they have to make to care for that person. In the view of the authors, a situation like this is best dealt with when all the people involved are seen with empathy, and not labelled but understood.

\section{Dementia: loss of personhood}

Personhood implies a sense of recognition, respect and trust. Kitwood (5: p 91), emphasises that social recognition of the individual builds personhood. In each of the novels, the individual's connections with the family are eroded, and this hastens the dementia in them. As we see in all three novels, the space of the family becomes the site of heightened vulnerability for the individual.

Bryan Turner (6: p 31), argues that the "social and political precariousness", included in his study of social ontology of human beings, means that political and social institutions fail to protect the interests of individuals when they collapse. And the people who are embedded in or dependant on them become highly vulnerable. This failure of the social institution of family is seen most acutely in the case of people afflicted with dementia. In the instances of Diwan Sahib, Kamala and Nana, the immediate family becomes the source of heightened vulnerability and serve as the instrument of negligence and exploitation. Nana's daughter plans to send Nana to an old age home. "It's air-conditioned of course, with a pool, spa, clinic, 24-hour medical help on call, hospital, theatre, full service and so on and he should be very happy there" (3: p 119). Kamala grieves over being reduced to an object to be looked after, losing her subjective agency "But no one asked for my choice, the doctor at the hospital changed the prescription and Siddhartha started giving me my medicine as per the new prescription (4: p 236). Diwan Sahib complains about Veer; his illegitimate son, not even visiting $\operatorname{him}(2)$.

In these novels, dementia is seen as a sign of the loss of domestic integrity itself: Nana can no longer entertain the grandchildren: "Well, General Gos, 'he told me one night, stroking my hair and sitting down on (the) bed.' This old general is fading away, so you will be in command soon" (3: p 99). Kamala can no longer function with any degree of efficiency; she is entirely dependent on her care-giver Siddhartha. "He woke me up in the morning, decided when I could go for my bath, when to have meals, when to have my medicines, what to cook, what to wear, when to go for a walk" (4: p. 229). Diwan Sahib, already disillusioned with his "nephew", loses all interest in the very objects that sustained his personhood - his durbar, his knick-knacks and his 
documented memories. As his friend Maya expresses "When I sat by him, and talked to him, his eyes sometimes changed expression, but often he shut them and turned away as if it was unbearable to be reminded of the world outside his cage"(2: p 197).

There are, however, redeeming moments and relationships: Kamala's recognition of her sister-in-law's scheming to claim her (Kamala's) property (4); and Diwan Sahib's alertness to the true purpose of Veer's sudden affection (2). While their everyday efficiency as persons might be eroded, parts of their perceptual and emotional abilities are unimpaired.

The trauma of an individual's dementia is a family trauma. The loss of rational processes and memory is also associated with the erosion of family memory. Moore and Qabaha (7) have proposed that individual memory functions within frameworks such as the family. When the networks begin to collapse, there is no longer a framework for individual memories. For instance, in Our Nana was a Nutcase, the old man is surrounded by his teenaged grandchildren, as he does not have his children around him (3). With Nana not having his children around him, his framework of memories built around his children would have begun to collapse.

In Silver Haze, with children and grandchildren moving away, the deterioration of Kamala's gendered role (the role that she had played all her life, which gave purpose to her life), is hastened by the lack of work as mother, grandmother and mother-in-law (4). In The Folded Earth, Maya witnesses the old Diwan burning all the documentary evidence of his family memories, since he has no one to pass them on to (2). We are made aware that Diwan Sahib lies in the hospital bed "Gagged into silence by tubes and masks" (2: $p$ 197). He is in an "unreachable zone" in his head, from which he does not wish to recall the world outside. His "nephew"Veer is not present to offer care and support at this stage, about which he makes cutting remarks. The medical interventions do not solve the problems of Diwan Sahib. So both familial and medical contexts fail him (2).

In Silver Haze, Kamala records:

Our bedroom was now reduced to being only my bedroom. It was painful for me to see my husband in the condition he was in and I spent most of my time alone there. This pain was redoubled by my loneliness. Everyone in the house was working like cogs in a well-oiled machine. Only I didn't know what to do.... We had hired a male nurse to make sure of 24 hour nursing that Jatinder required. I was quite alienated and my dementia symptoms worsened. It was in this condition that I was taken to the hospital by Kamal and my diagnosis confirmed. (4: p 226)

Kamala's deterioration is linked to her husband's illness, not to her medical treatment or diagnostic processes. While the medicalisation of home becomes the instrument of healing for her husband, it furthers Kamala's distancing from the remainder of both her family and the spaces she deemed her own, and aggravates her dementia (4).

When we think of family trauma as a framework within which the individual "case" of dementia might be examined, the medical paradigm intersects and interacts with this framework.

If we look at the teenaged characters of Lal's novel: their suspicion of hospitals and of their parents has made them kidnap their Nana and situate their caring for him in the farm house, a task which their family as a single unit has failed to do. They take this drastic decision because their parents have decided to admit their beloved grandpa into a care home for elders.

A comment made by the eldest, Avantika is: "And now, Mama and Papa wanted to destroy our 'family life' with him, because it did not quite fit into their scheme of things - into the brilliance of their lives. How could Mama think of selling Shadow House?" (3: p 124).

The theme of dementia like the theme of geriatric medicine enables Indian writers to subtly criticise the hitherto glorified Indian family, which is often seen as a miniature of the nation itself.

The grown up children of Kamala in Silver Haze (4), the teenaged grand children in Our Nana was a Nutcase (3) realise that the atmosphere of the family is no longer warm, secure and predictable - the disease overturns the patterns of everyday life. The home is no longer a relaxed space, but has been converted into a Gothic structure alien to the aged. Kamala cannot navigate her route between rooms, Nana can no longer climb stairs, and Diwan can no longer mimic the voices of birds.

Dementia alters the relationships: the uncertain behaviours the unpredictable actions of persons with dementia affect the energies and equations of relationships of family members in a subtle way. The highly efficient Kamala (4)), the energetic Nana (3), and the patriarch Diwan (2) were fiercely independent, good caregivers and were always giving orders, before the onset of dementia. But as the dementia progresses, their orders become absurd, irrational and chaotic. The children who were dependant on them now become their caregivers. Servants become their mainstay, and nurse/helpers issue orders to the patients.

The patients get dislocated from home: literally and figuratively. They no longer identify themselves with the familiar spaces of home, which they have controlled for years. Kamala does not participate in any of the activities at home, Nana sits idly in his Cadillac SUV, and Diwan withdraws himself totally into the house. Their personalities are diminished to pale shadows of their former selves.

Kamala, Diwan and Nana, dependent upon nurses and maids like children, cannot comprehend the daily chores in their homes. The distinction between loved ones, relatives and visitors breaks down as the three of them drift in and out of 
the home. For the person with dementia, the home is no longer quite like home. The alteration of the space into the un-homelike as a result of the dementia changes everything for everyone forever.

Characters like Mama and Papa in Our Nana was a Nutcase and Veer in The Folded Earth do not find any solace in the idea of home as they are metaphorically homeless. The novels also suggest that dementia cannot simply be a mere subject of hospitalisation or a mental condition. The texts return to the family as a stable, safe and recuperative space.

\section{Family as recuperative space}

While healthcare professionals are involved in the daily care of the patient, the primary responsibility for care is invested in the family. If family is presented as the space where the situation of the person with dementia becomes worse because of accompanying indifference or inefficiency, the same texts also suggest that despite these conditions, the family remains the best place for those with dementia. It is the family which provides the set of rituals and actions of the individual from happier days that continue to give meaning to the person living with dementia.

Thus, in an epilogue in Silver Haze, the son as a narrator says that Kamala walks around the garden with the nurse and finds it very amusing (4). In Our Nana was a Nutcase, the old man's day is organised around repetitive actions from his grandchildren. "We try and remind him [their grandfather] every day [of his family] ... like his medicine" (3:p 233). The key aspect here is the grandchildren give Nana a set of verbal reminders to keep his memory sharp, as they keep reminding him to take his own medicines. The children revolt when their parents decide to admit the old man to a long-term care facility. When their mother argues that he will be well looked after, the children's response is emphatic - "care is what we do here in this house" (3)

In Silver Haze, there is the hiring of a healthcare professional, but the other two novels depict a loyal, caring class of people who attend to the patient's every need. Nana in Our Nana was a Nutcase is surrounded by his grandchildren; Diwan Sahib in Folded Earth is well taken care of by loyal and faithful servants (2).

The erosion of immediate family relations and dissipation of family structures and failure of cultural protection has been anticipated in the case of persons with dementia. The cultural protection is restored when re-emplacement is initiated, within the frame of the home, but perhaps by a different set of people and relations. Here, the idea of cultural protection represents the notion of care, consideration, acceptance and assimilation that is provided to elderly members of society. With proper care, these aspects of protection can be restored for people afflicted with dementia. The relaxed spaces or recuperative spaces are built in these novels by the erasure or blurring of borders. The "dependent" become the caregiver and the outsider turns into an insider through altered social relations.

Here an important question arises as to how much society can expect a family to do for persons who have lost their personhood, their memories, their past and their understanding. If memory can only be seen in relation to others and is a cultural construct, then that has evaporated too. In such circumstances, when total personhood is lost, it becomes a question of caring for a body but not the person, because the person is no longer there.

Maya, who rents a cottage near Diwan Sahib's house, is the most trustworthy caregiver and constantly in his home in The Folded Earth (2). Shabby (Shabnam) Aunty, though not a family member, in Our Nana was a Nutcase, becomes more or less a permanent member of the house. The grandchildren kidnap their ailing Nana in Our Nana was a Nutcase, hide him and care for him, when the parents try to shut him away in a nursing home. Thus, the safety and security of the family is threatened by the intentions of the parents to sell off the ancestral property. In The Folded Earth, the unwanted attention of Army officers' to Diwan Sahib's property and Veer's indifference both establish the concept of collapsing social boundaries that are expected to safeguard the home space.

\section{Dementia in different settings: the medical vs familial approach}

By the very nature of the disease, dementia has touched physical, medical and ethical realms to a substantial degree. It has raised questions about the integrity of society and family which are very difficult to answer, just as medicine is still trying to find the causes and remedies for the disease.

When a person is diagnosed with this disease; his entire personality is put under the medical, societal and familial scanner. His intellectual dignity is deeply hurt when he is asked very simple questions by clinicians ...such as what month of the year it is; or what day, or which year. He might be a university maths professor but still has to answer questions suited to a toddler. Not just this, the person so afflicted by the disease has to contend with people who might take the responses adversely, not understanding that this phenomenon is a direct symptom of the decline in mental abilities.

Due to lack of awareness in developing countries like India, families might take longer to understand the complexities of this disease. The usual caretakers can be daughters in law or daughters or any other family member. They are constantly threatened by the darkest question, "Who is this person they care for?" The patient is no longer the same. He can neither show gratitude nor appreciation as is generally shown by those receiving care.

All this is particularly difficult to understand in a holistic sense in a close-knit family setting, especially in a society like India, where family elders are looked up to as a source of inspiration and wisdom. When these elders are themselves not in a 
cognitive space to provide such advice, they might just end up losing their position in the family.

From a medical perspective, dementia is understood in a pretty straightforward way. While it is understood to be a disease and to have certain effects, its causes are yet unknown; and while it can be diagnosed, it cannot be cured, as yet. Essentially, there is a way to "treat" dementia but there is no way to "cure" it.

Another aggravating circumstance is that the treatments that are accorded to dementia patients often have side effects that further harm the dignity of the individual. The individual in question might be relegated to a positon of numbness, fatigue or irritation, one common side effect being that the patient loses control over his bodily functions leading to side effects that are quite demeaning, such as involuntary release of saliva from the mouth which falls to the floor.

One critical ethical question that comes to the fore surrounds the idea of medication, the ethical question relating to how effective the medication is, in the realm of curing versus how effective it is in managing and mitigating the symptoms. The ethical question would be "What is the way forward: medicating the individual with no hope of cure in a bid to prolong life with symptoms? Or medicating to a degree that might not prolong life to a great degree, but would help the patient live whatever life is left with dignity?"

\section{Concluding remarks}

The important point which emerges in these three novels is that when the atmosphere of home becomes unsettling due to the onset of dementia; it can be resettled with the support system of servants, neighbours and friends, making for a constant process of unsettling and resettling. A different set of social relations is built around the person with dementia when the difference between "family" and "outsider" blurs, and the home space gets transformed into a recuperative space. An understanding of the limitations, effects and benefits of such a recuperative space would help families make better decisions.

Such an understanding can only take place once ethical questions surrounding the situation are posed and thought through, and while there might be no correct answers, the questions themselves could form a basis of understanding for the families and the patients, thereby leading to a more holistic and better informed recuperative state.

Literature can give us a tremendous understanding of such questions for different settings and nations: here, these Indian novels point to the fractured homes, the instability of families, and the uncertainty that looms over previously secure spaces. These novels address the issues with a realistic portrayal of Indian families that take stock of themselves and change considerably to adapt to the vastly different circumstances that the disease creates.

Conflicts of interest and funding: No financial or other conflicts or funding declared.

\section{References}

1. Alzheimer's Association website. 10 early signs and symptoms of Alzheimer's. 2016 [cited 2020 Mar 23]. Available from: https:// www.alz.org/alzheimers-dementia/10_signs

2. Roy A. The Folded Earth, London: Quercus Publishing; 2011.272 pgs

3. Lal R. Our Nana was a Nutcase. Red Turtle, Rupa, 2015, 234 pgs.

4. Verma P. Silver Haze, Create space Independent Publication, May 2014.

5. Kitwood, T. Dementia Reconsidered: The Person Comes First. Adult lives: A life course perspective (2011). pp. 89-99.

6. Turner BS. Vulnerability and human rights, Pennsylvania University of Pennsylvania Press, 2006.

7. Moore L, Qabaha A. Chronic trauma, (post) colonial chronotopes and Palestinian lives: Omar Robert Hamilton's Though I Know the River is Dry [Ma'a Anni A'rif Anna al Nahr Qad Jaf.] In:Ward A, (ed). Postcolonial traumas: Memory, narrative, resistance. London: Palgrave-Macmillan; 2015. pp. 14-29. 